\title{
Loculated pleural effusion caused by Legionella pneumophila
}

\author{
AP FREEDMAN, E COODI,EY, RF JOHNSTON, L GOODMAN, SM KATZ \\ From Hahnemann Medical College and Hospital, Philadelphia, and Long Beach VA Hospital, Long Beach, \\ California, USA
}

Legionnaires' disease is primarily a pneumonic illness, though gastrointestinal, renal, and hepatic dysfunction are often present. Pleural effusions are relatively common but not clinizally significant. ${ }^{1}$ We wish to report a case of infection with Legionella pneumophila that manifested as a loculated pleural effusion with minimal involvement of the lung.

\section{Case report}

A 42-year-old male teacher was admitted to hospital with a three-week history of cough, chills, night sweats, and 10 pound weight loss. Oral ampicillin, $500 \mathrm{mg}$ qid, had been started one week before admission when a right pleural effusion was noted on his chest radiograph and the white blood cell count was found to be $38000 \mathrm{~mm}^{-3}$. Despite this therapy, his cough became productive of white to yellow sputum and he developed right pleuritic chest pain. He was a 60 pack year cigarette smoker but had had no previous pulmonary illness. He denied seizures, excessive alcohol ingestion, or loss of consciousness. He had cleaned out an attic containing a pool of stagnant water several days before the onset of his symptoms.

On physical examination, he was in no distress. Respirations were 18 per minute, pulse 116 , and temperature $37 \cdot 2^{\circ} \mathrm{C}$. Myringitis, rash, and adenopathy were absent. Moderate periodontal disease was noted. The lungs were clear to auscultation and percussion. Cardiac and abdominal examinations were normal. There was a suggestion of clubbing (which had been present since childhood) but cyanosis was absent.

The white blood cell count was $27100 \mathrm{~mm}^{-3}$ with $85 \%$ segmented neutrophils, one band, and no eosinophils. Routine blood biochemistry was normal except for elevation of SGOT to 51 units $1^{-1}$ (normal up to 40 ), and elevation of the alkaline phosphatase to 212 units $1^{-1}$ (normal up to 85). Arterial blood gases showed a pH of 7.47 , a $\mathrm{PCO}_{2}$ of $31 \mathrm{mmHg}$, and a $\mathrm{Po}_{2}$ of $59 \mathrm{mmHg}$ on room air. The chest radiograph (fig 1) revealed several pleural-based densities at the apical, anterior, and posterior aspects of the right upper hemithorax which had progressed in size between 9 and 23 July. Serum

Address for reprint requests: Dr Allan P Freedman, Hahnemann Medical College and Hospital, 230 North Broad Street, Mail Stop 107, Philadelphia, PA 19102, USA.

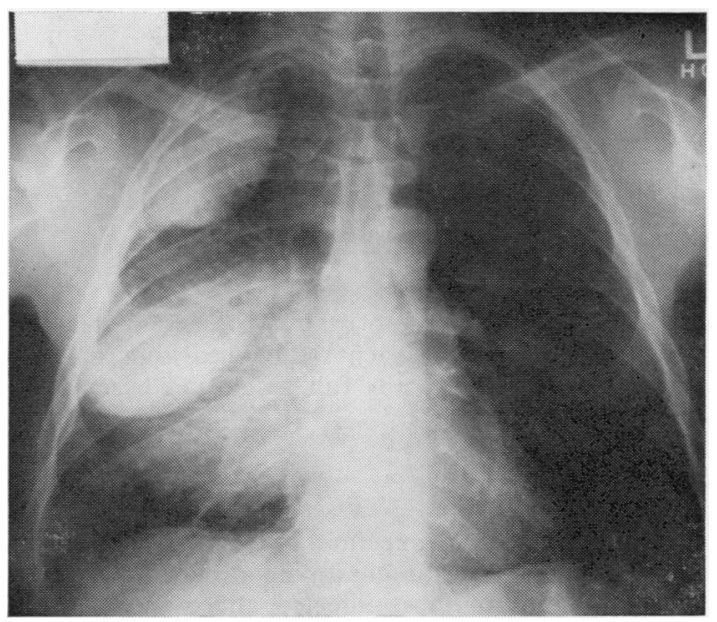

Fig 1 Chest radiograph reveals several pleural-based densities at the apical, anterior, and posterior aspects of the right upper hemithorax.

antibody titre to Mycoplasma pneumoniae was < $1: 8$.

Fluid aspirated from the anterior pleural pocket was turbid. Cytology of the specimen was normal. Pleural fluid glucose concentration was less than $5 \mathrm{mg} \%$, protein was $5.9 \mathrm{gm} \%$, and $\mathrm{LDH}$ was greater than 1000 units $1^{-1}$. There were 1440 red cells and 110 white cells per $\mathrm{mm}^{3}$. Pleural fluid cultures processed both aerobically and anaerobically for bacteria were negative, as were special stains and cultures for mycobacteria and fungi. Direct fluorescent antibody staining of the pleural fluid, as described by Cherry et $a l^{2}{ }^{2}$ showed $4+$ profusion of cocco-bacillary organisms both within and outside of neutrophils and macrophages (fig 2). Serum antibodies to Legionella pneumophila measured by the indirect fluorescent antibody technique, ${ }^{3}$ were present at a titre of $\geqslant 1: 512$ in convalescent serum and dropped to $1: 128$ six months after discharge. Both serum samples retained their level of antibodies to Legionella pneumophila after preabsorption with six different stains of Bacillus fragilis. Also, serum antibodies to Bacillus fragilis were absent.

Although the patient gradually became afebrile and asymptomatic during the three weeks of ampicillin 


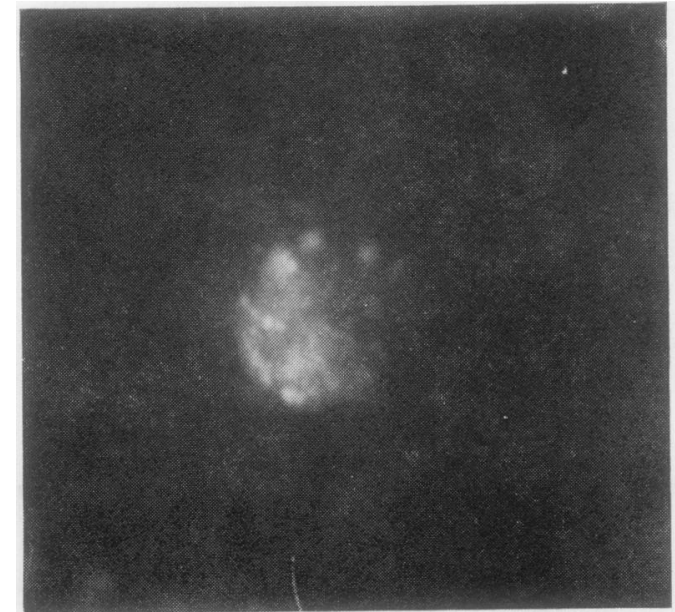

Fig 2 A macrophage in the pleural fluid contains intracytoplasmic aggregates of Legionella pneumophila antigen (Direct immunofluorescent test $\times 400$ ).

therapy, he was switched to oral erythromycin stearate $500 \mathrm{mg}$ qid because of persistent radiological abnormality. One month later there was full resolution except for residual pleural scarring.

\section{Discussion}

Pleural involvement in infection by Legionella pneumophila is common. Pleuritic chest pain occurs in approximately one-third of those infected and a pleural rub may be heard. ${ }^{1}$ Pleural effusion, usually unilateral, is associated with the pneumonic illness in less than onethird to over one-half of reported cases. ${ }^{4-6}$ In some cases it has been considered secondary to associated congestive heart failure. ${ }^{6}$ Though effusions may precede the pneumonic infiltrate, most coincide with it.4 ${ }^{5}$ None has been reported without a pneumonic infiltrate.

Pleural involvement with Legionnaires' disease has not been clinically significant except in patients receiving corticosteroids. ${ }^{7}$ Empyema from Legionella pneumophila has not been described, though the organism has been found in pleural fluid. ${ }^{2}$ The few pleural fluid analyses reported showed the effusion to be either an exudate or transudate, to have a variable leucocyte content, and to have a normal glucose concentration. ${ }^{14} 78$ Though pulmonary cavitation has occasionally occurred, especially in immunocompromised patients, pleural loculation has not been reported. ${ }^{7} 810$

Our patient had infection with Legionella pneumophila documented by demonstration of the organism in pleural fluid and a high convalescent titre of antibodies to the organism. The pleural fluid was an exudate and its glucose concentration was extremely low, even though fluid leucocytosis was minimal. Legionella pneumophila must now be considered in the differential diagnosis of both loculated pleural effusions and pleural exudates with low glucose concentrations.

This work was supported in part by NIH grant number 1 R01 AI15593-01. We are grateful to Ms Joan Smith for assisting in the preparation of this manuscript.

\section{References}

${ }^{1}$ Swartz MN. Clinical aspects of Legionnaires' distase. Ann Intern Med 1979;90:492-5.

${ }^{2}$ Cherry WB, Pittman B, Harris PP et al. Detection of Legionnaires' disease bacteria by direct immunofluorescent staining. J Clin Misrobiol 1978;8:329-38.

${ }^{3}$ Wilkinson HW, Fikes BJ, Cruce DD. Indirect immunofluorescence test for serodiagnosis of Legionnaires' disease. Evidence for serngroup diversity of Legionnaires' disease bacterial antigens and for multiple specificity of human antibodies. J Clin Microbiol 1979; 9:279-83.

${ }^{4}$ Tsai TF, Finn DR, Plikaytis BD, McCauley W, Martin SM, Fraser DW. Legionnaires' disease: clinical features of the epidemic in Philadelphia. Ann Intern Med 1979; 90:509-17.

${ }^{5}$ Kirby BD, Peck M, Meyers RD. Radiographic features of Legionnaires' disease. Chest 1979;76:562-5.

- Dietrich PA, Johnston RD, Fairbank JT, Walles JS. The chest radiograph in Legionnaires' disease. Diagnostic Radiology 1978;127:577-82.

7 Winn WC, Glavin FL, Perl DP, Craighead JE. Macroscopic pathology of the lungs in Legionnaires' disease. Ann Intern Med 1979;90:548-51.

${ }^{8}$ Levin S, Brettman LR, Goldstein EJC et al. Legionnaires' disease: a cause of severe abscess-forming pneumonia. Am J Med 1979;67:339-42.

${ }^{9}$ Gump DW, Frank RO, Winn WC Jr, Foster RS, Broome CV, Cherry WB. Legionnaires' disease in patients with associated serious disease. Ann Intern Med 1979;90:53842.

${ }^{10}$ Saravolatz LD, Burch KH, Fisher E et al. The compromised host and Legionnaires' disease. Ann Intern Med 1979;90:533-7.

\section{Books received}

Medical and surgical problems of the esophagus.

S Stipe. London: Academic Press, 1981. $£ 25.00, \$ 60.00$. 